Original Research Paper

\title{
Investigating the Behavior of Steel Composite Shear Wall with Corrugated Plate under Lateral Load
}

\author{
Seyedeh Asma MirfazliJirdehi \\ Master Graduated Student, Rouzbahan University, Sari, Iran
}

Article history

Received: 11-09-2018

Revised: 18-06-2018

Accepted: 06-07-2018

Email:

seyedehasmamirfazli@gmail.com

\begin{abstract}
The steel shear wall system has been considered as a structural system over the past few decades. This issue deals with wind and earthquake lateral forces due to its hardness, loading capacity and plasticity. This type of the system, with the use of external hardness resulting from the geometric shape of the waves, has better buckling strength than a hardened and smooth mood. In this paper, at first, the experimental test is validated with ABAQUS software which simple rectangular steel plate was used in the shear wall so that both cyclic and monotonic loading conditions have been compared Since then the concrete shear wall behavior has been evaluated using sinusoidal steel plates with different variables such as concrete compressive strength 25 and 35 MPa thickness of corrugated plate including 0.8 and $1 \mathrm{~mm}$ and wave height 25 and $50 \mathrm{~mm}$ are considered as variables. The interaction between concrete and steel is applied using Tie and the base of the wall is fixed. Moreover, the sample is loaded in accordance with the ATC24 instruction with a displacement of $85 \mathrm{~mm}$ using displacement/rotation by activating U1 direction as lateral load. Generally, eight different models have been evaluated and the pushover graphs are compared based on thickness and concrete strength. The results show that increasing the thickness, the wave height and the compressive strength of the concrete leads to increased resistance and ductility.
\end{abstract}

Keywords: Steel Shear Wall, Corrugated Sinusoidal Plate, Static Loading, Pushover Resistance, ABAQUS Software

\section{Introduction}

Steel shear walls have been given special attention to structural engineers for retrofitting steel structures over the last 15 years. Its unique features have attracted more attention, its features are economical, easy to use, low weight compared to similar systems, high ductility, quick installation, high energy absorption and a significant reduction of residual stress in structure. Steel shear walls are an innovative system that is resistant to lateral loads of wind and earthquakes, like wind turbines, but perform better than other systems such as momentresisting frames as previously studied by Fanaie et al. (2015a), Kazerani et al. (2017). The main purpose of using the steel shear wall as a structural system in the building is to withstand the shear forces and reverse anchors due to lateral loads. This system is made up of a steel panel surrounded by a steel frame and its used in the form of stiffened and unstiffened. The idea of using corrugated sheets to remove hardeners in steel shear walls has been proposed in recent years which causes practical issues in welding the stiffeners to increase the buckling capacity of the steel plates by Haddad et al. (2018). This novel idea has been used for many years in many fields of Civil Engineering such as Geotechnical Engineering such as the research which performed by Nakhostin et al. (2017) to increase the buckling capacity of the corrugated pipeline. Significant initial stiffness, sufficient ductility, high ability to dissipate energy and possessing particular geometry are among the main reasons for this review. Theoretical studies show that using a shear sheet of corrugated steel removes the bending and cutting interaction and on the other the hand, increases the strength of the wall before buckling. In this regard, numerous laboratory and theoretical studies have been carried out by various researchers, most of the experiments have been conducted on a non-hardened steel shear wall under static loading and cyclic loading based on the proposed criteria. The first comprehensive study was carried out on a real steel shear wall by Driver et al. (1997). They compared the results a four-stage steel shear wall by one spout with real scale under the periodic loads and by finite element analyze of 
experimental model. The test specimen was fitted with flexural beam-column and placed under equal horizontal forces equal to each floor level. Meanwhile vertical loads applied to the columns in a measure of gravity loads for a conventional building. The test response was a highly volatile behavior and the hysteresis curves were relatively large, indicating significant energy absorption. One of the limitations of the steel shear wall system is that the materials available for the wall may be stronger and thicker than the amount required for design. Berman and Bruneau (2003) to solve this problem, investigated the use of cold-formed galvanized steel sheets. Low-yielding steel and holes to reduce the strength and hardness of the steel panel. This specimen reached to $12 \%$ ductility and $3.7 \%$ drift and the wall plate provided $90 \%$ of the initial hardness of the system. The extreme state of the sample was created due to the rupture in the sheet, which began to expand from the corners. Emami et al. (2013) conducted periodic loading tests in three simple shear walls and two trapezoidal corrugated shear walls. All specimens were of the same size, half real dimensions, one floor and one span with sections of the beam and column, as well as a very similar connection and in all three samples, the thickness of the shear sheet was taken to be exactly the same as $1.25 \mathrm{~mm}$. By performing experiments, it was found that a simple shear wall has a higher final strength and is about $17 \%$ higher than the rippling specimen and reducing hardness in it is by gradually entering the plastic axis. The total energy absorbed in the corrugated samples is about 52\% higher than the simple sample. Hosseinpour et al. (2015) compared and study the shear wall with corrugated plates. In this study, nonlinear behavior of the steel shear walls with corrugated plates modeling in pushover condition and analysis is by finite element method and the results showed that by increasing the thickness of the corrugated plate in the steel shear wall, the final capacity, ductility and energy dissipation increase significantly. Increasing the hardness of boundary elements, such as the beam and the column, has increased the degree of ductility and the final capacity about 3 to 15 percent and comparison of the results for sinusoidal and trapezoidal corrugated plates shows that trapezoidal corrugated plates perform better. $\mathrm{Yu}$ and $\mathrm{Yu}$ (2016) empirically studied the cold-formed steel shear wall using corrugated steel sheets by circular hole. The corrugated steel coating significantly increases the strength of the cold-formed steel shear wall, but the walls ductility is debatable. Shear walls increase ductility due to a new failure condition, However, the stiffness and shear strength of the walls are significantly reduced. Therefore, the authors do not recommend the use of circular holes in corrugated sheets for a cold-formed steel shear wall to provide resilience. Faramarzpour and Laman Jeffrey (2015) examined the behavior of corrugated steel shear wall with opening. This study has been numerically compared corrugated and simple steel plate, with and without opening. The results show that the use of trapezoidal corrugated plate increases the initial hardness and energy absorption and reduces the final strength. Rahnavard et al. (2016) examined numerical parameters of the concrete-steel composite shear wall. ABAQUS software was used for modelling. Important parameters include concrete breakdown, hysteresis curve, displacement and energy dissipation, which were studied in laboratory and numerical comparisons. Numerical results show that the buckling of the shear wall steel plates is reduced by increasing the thickness of the concrete and eliminating the contour gap leads to increased energy dissipation. Also, Fallahi et al. (2018) did comparison o numerical analysis using ABAQUS and experimental test. He applied lateral loading conditions using seismic behavior of cyclic loading to check the validation of finite element software. Since then, he used pushover analysis with the same concept to check the load capacity of different samples. Prabha et al. (2017) evaluated the behavior of panel inside the composite panels of concrete-steel foam under lateral load. The use of this type of composite panel as a shear wall leads to increased seismic resistance which is almost identical the composite beams that has been studied with different arrangements of channel shear connectors by Fanaie et al. (2015b). Also, Shabana and Alibeigloo (2017) reviewed three methods for sandwich panels with corrugated core under the energy method. To do this, they used three-dimensional pull theory. Using this method leads to more precision and more sensitivity than other methods.

\section{Laboratory Sample}

Developing a confident finite element model is essential for an applied analysis. Therefore, revision of model validity is one of the most important and necessary steps in a study. For this purpose, a number of test samples, the result of which have taken in practice, are numerically simulated using a threedimensional model and the accuracy of the above model is controlled by the use of relevant results, so how much this modeling approaches the laboratory condition, it will reduce the error and achieve more realistic results in the software. The selected shear wall is $100 \mathrm{~mm}$ thick, $1000 \mathrm{~mm}$ wide and $3000 \mathrm{~mm}$ long, as shown in Fig. 1. The compressive strength of the wall is $25 \mathrm{MPa}$ and the yield stress and tensile stresses of the longitudinal bars are $479 \mathrm{MPa}$ and $616 \mathrm{MPa}$, respectively and this values for transvers bars are 548 and $622 \mathrm{MPa}$. The arrangement of the bars is shown in Fig. 1 (Dan et al., 2011).

Also, in Fig. 2 and 3, the cross-section details and the loading profile are visible, so that the maximum range is 8 and the lowest is $\mathbf{- 8}$. On the other hand, the loading time is $15 \mathrm{sec}$. 


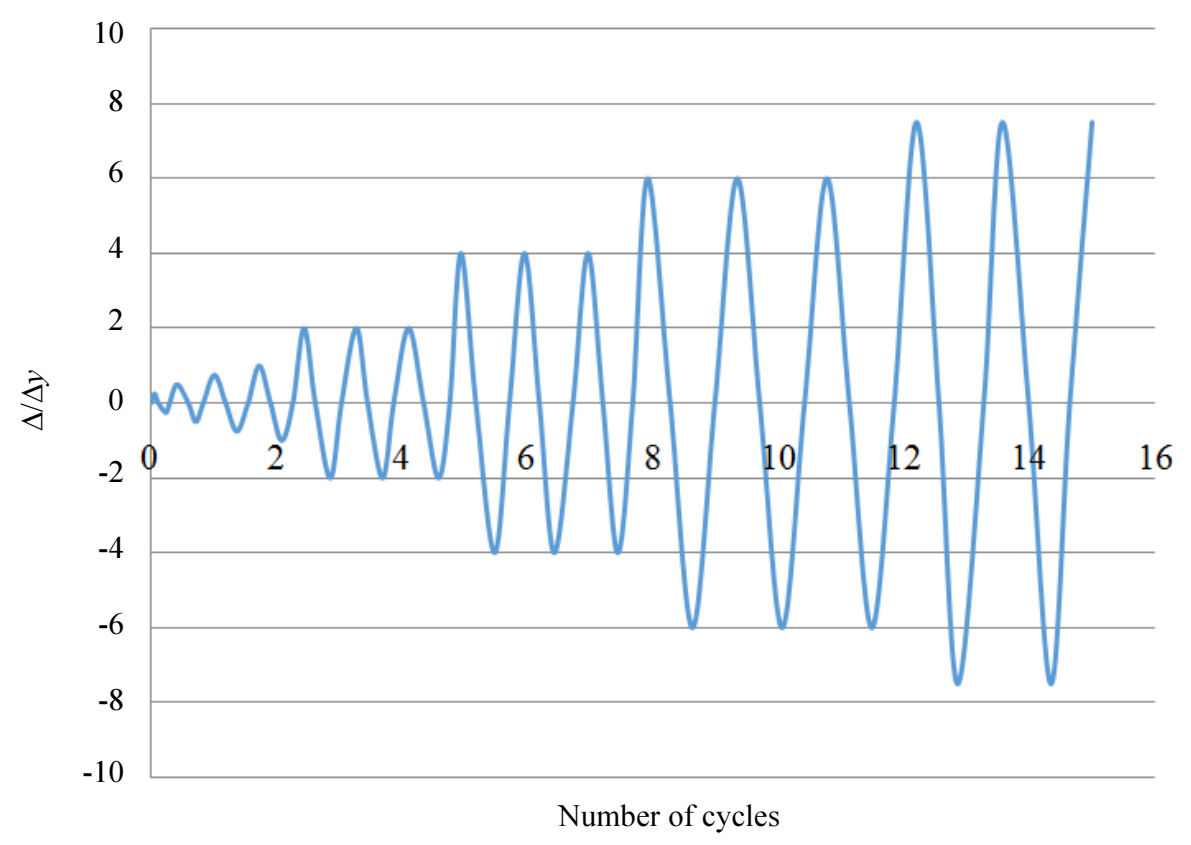

Fig. 1: cross section of the wall (Dan et al., 2011)

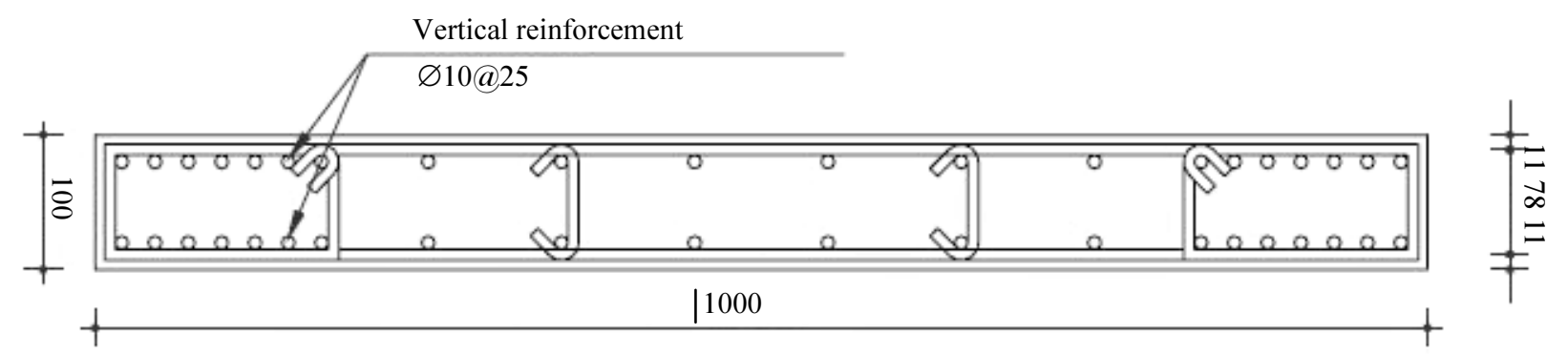

Fig. 2: Cross Section Details (Dan et al., 2011)

\section{Modeling in ABAQUS}

This section deals with the modeling in ABAQUS. Solid elements are used in concrete wall modeling and for barrels, longitudinal bars are used. Elements of the beam are used to define longitudinal bars. This element has the ability to consider the shear force in addition to the axial force in two directions perpendicular to each other. However, for the purpose of introducing transverse cross sections, the properties of truss elements, which only axial force are tolerated in two directions perpendicularly, is used. The bottom line is to define the concrete behavior in which concrete damage plasticity model has been used by SayyarRoudsari et al. (2018a; 2018b), Soleimai and SayyarRoudsari (2015) who did some numerical methods to define and compute the different parameters of the concrete behavior. In his study, he introduced some formulas to calculate the compressive and tensile stress and its corresponding strain. He also indicated to specific parameters of tensile and compression damages and its inelastic strain, too which has been validated by some theoretical and experimental results. This concrete behavior has been computed by the mentioned method. Also, Abu-Lebdeh and Voyiadjis (1993a; 1993b) and Voyiadjis and Abu-Lebdeh (1994) did parametrical studies on the concrete damage plasticity models. In his research, he evaluated the concrete parameters under different loading conditions such as cyclic loading. Moreover, his investigation for finding damage criteria of the concrete make a giant straight forward in parametrical modeling of concrete element in finite element software. In Fig. 4 and 5, the stress-strain diagrams of concrete behavior in the plastic zone are shown for compressive and tensile behavior, respectively. 


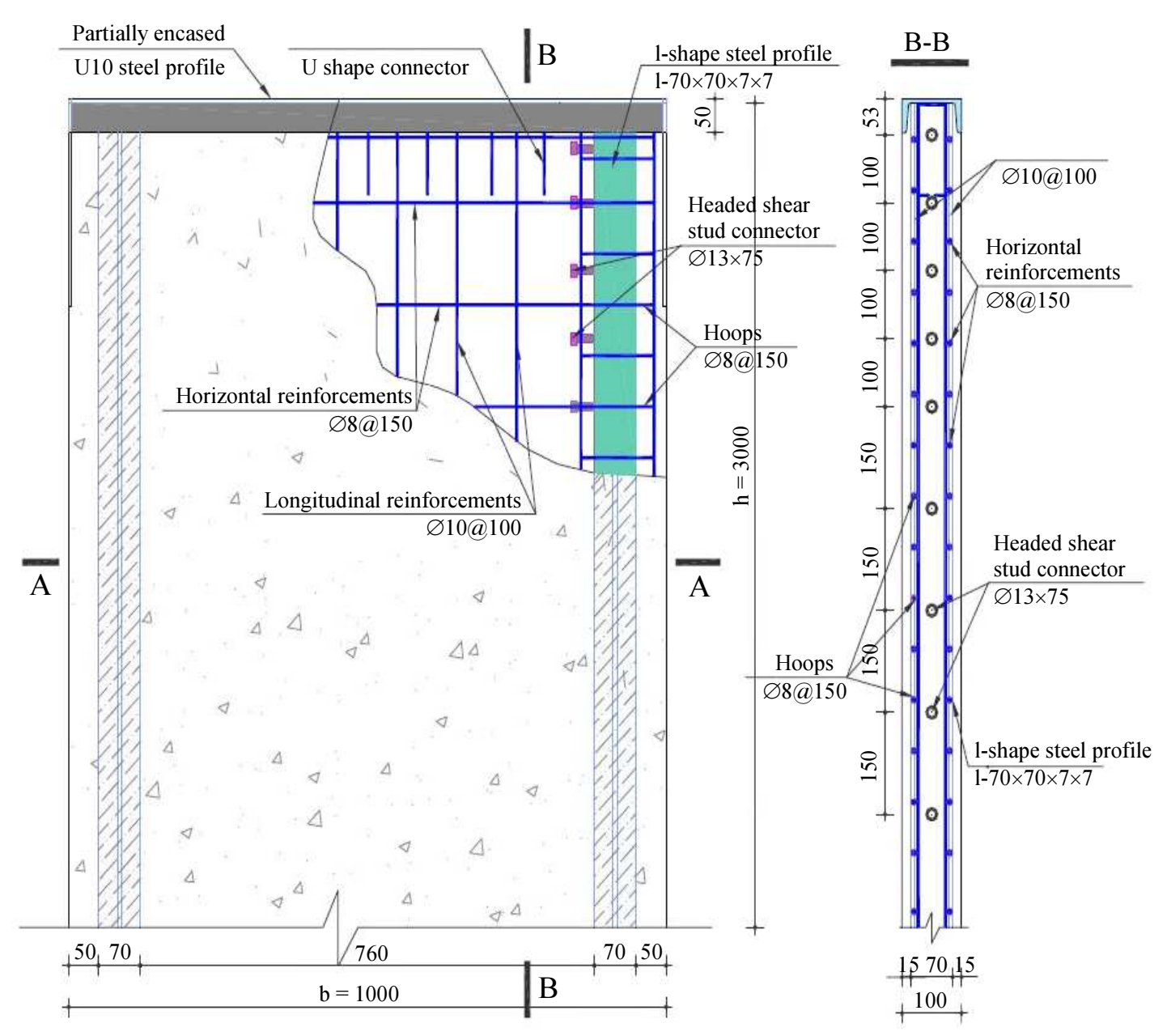

Fig. 3: Domain loading specification (Dan et al., 2011)

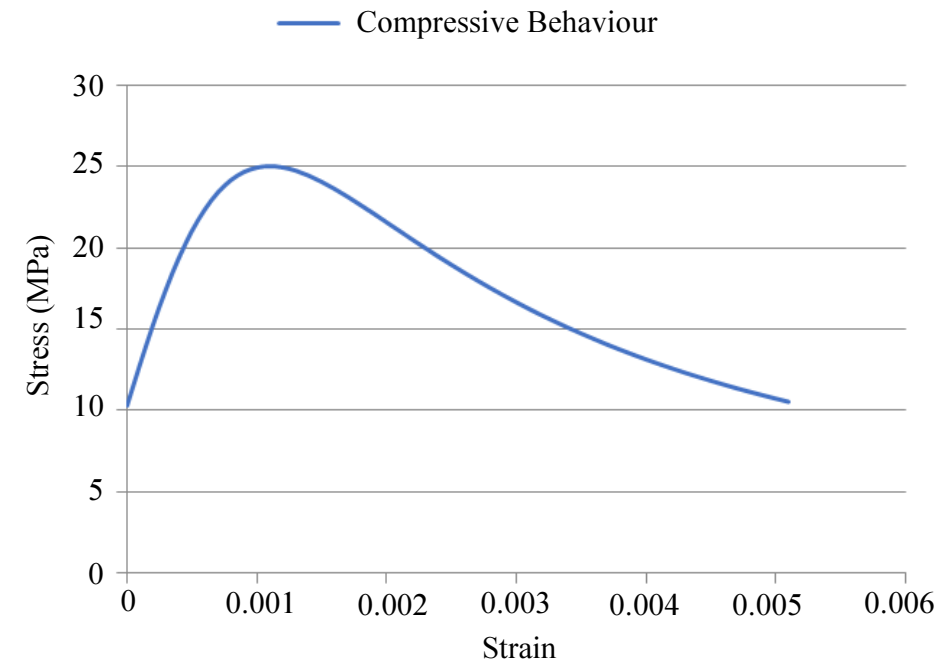

Fig. 4: Stress-strain of concrete damage plasticity in compression condition

According to $3 \mathrm{D}$ modeling, in order to provide the concrete behavior in this case, three-dimensional elements of eight-node C3D8R is used. $R$ suffix is used to reduce the integral points so that the duration of the program is 
reduced. For the introduction of longitudinal and transverse reinforcement, three-dimensional truss elements are used with linear deformations. In this type of element, the axial force is transmitted and no anchor of these elements is created. The reinforcements are individually defined with concrete elements and truss elements are embedded in concrete. Figure 6 shows how to assemble the model.

This type of analysis used in this model is static nonlinear. Given the back-and-forth analysis, the analysis time is based on the loading domain protocol of $15 \mathrm{sec}$. Also, Embedded Region is used to define the contact of concrete and Rebar and the contact surface of the IPE sections with the side wall of the concrete has been used with TIE. In the Fig. 7, the contact of elements is visible.

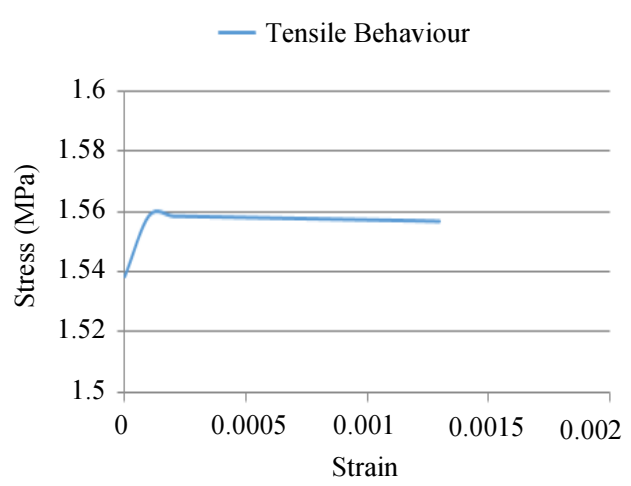

Fig. 5: Stress-strain concrete damage plasticity in tensile condition
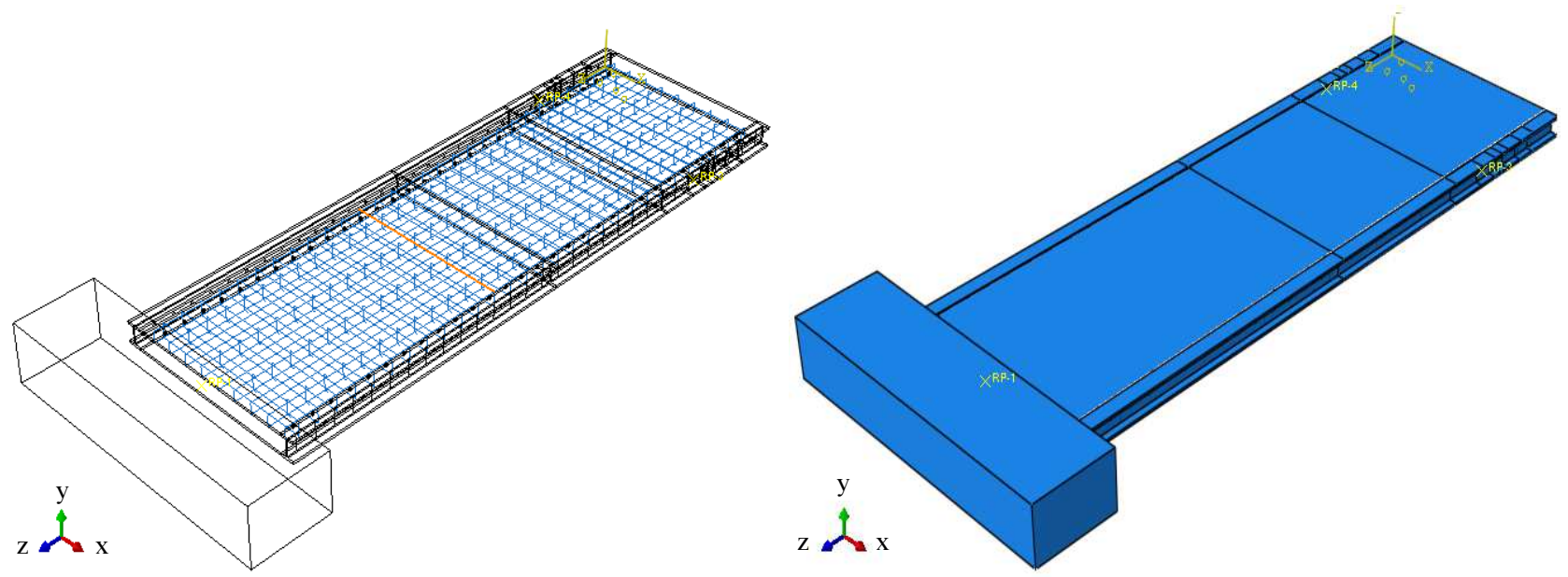

Fig. 6: Assembling details of the model

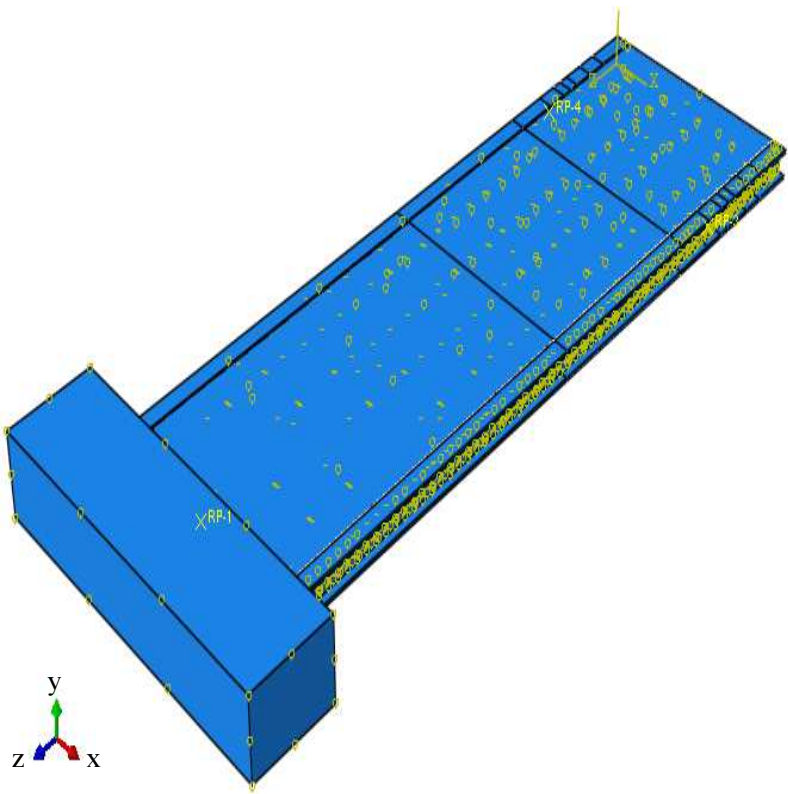

Fig. 7: The contact of elements

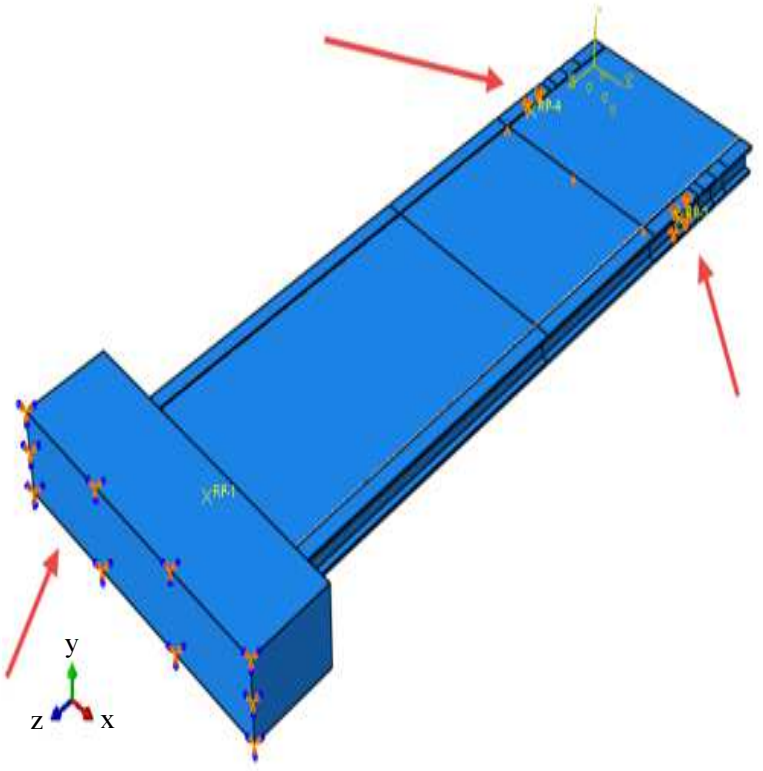

Fig. 8: Boundary Condition of Wall 
Also, the wall has fixed at the base of the wall, which is considered to be completely restrained and the loading is in the form of displacement-control, applied on both side of the model. In Fig. 8, the location of the loading and the gripping location is specified. The mesh of the concrete wall is TET elements and used by Mesh Study method (SayyarRoudsari et al., 2018; 2018). In Fig. 9, we can see the mesh of the model.

In this part the validation results are discussed. The force-displacement diagram shown in Fig. 10 is a comparison of numerical and laboratory results. As can be seen in the diagram, the maximal force obtained in the laboratory is $345.97 \mathrm{KN}$, which increases the maximum force in ABAQUS by $4.5 \%$ and reaches $363.77 \mathrm{KN}$. On the other hand, the displacement of the laboratory sample is $90.36 \mathrm{~mm}$, which is the result of software is $94.5 \mathrm{~mm}$. Due to the comparison of the results and the small differences between the software and the experimental, it can be concluded that the finite element model presented has an acceptable accuracy. Figure 11 shows the curvature of the pushover for the sample, in this case, the maximum force obtained from the modeling is 345.631 $\mathrm{KN}$ and the displacement value is $94.762 \mathrm{~mm}$, which corresponds to the laboratory sample, respectively $0.09 \%$ decrease and increased by $4.87 \%$ which is acceptable.

\section{Specification of Software Models}

Sinusoidal geometry plate is used to model the composite wall, which are made in the form of steel plate in the middle and a concrete wall on both sides. These sheets are modeled with a fixed step shown in
Fig. 12. The thickness of the sheets is 0.8 and $1 \mathrm{~mm}$, respectively and the strength of the walls is 25 and 35 $\mathrm{MPa}$ and the thickness of the wall is $25 \mathrm{~mm}$. As it can be seen in the Fig. 11, "d" and "e" are the wave height and wavelength, respectively.

For the modeling of the beam and the column IPE220 and IPE120 are used. The yield stress and ultimate stresses of steel are 280 and 500, respectively and the modulus of elasticity of steel is $204000 \mathrm{MPa}$. Table 1 presents the characteristics of the model sheets.

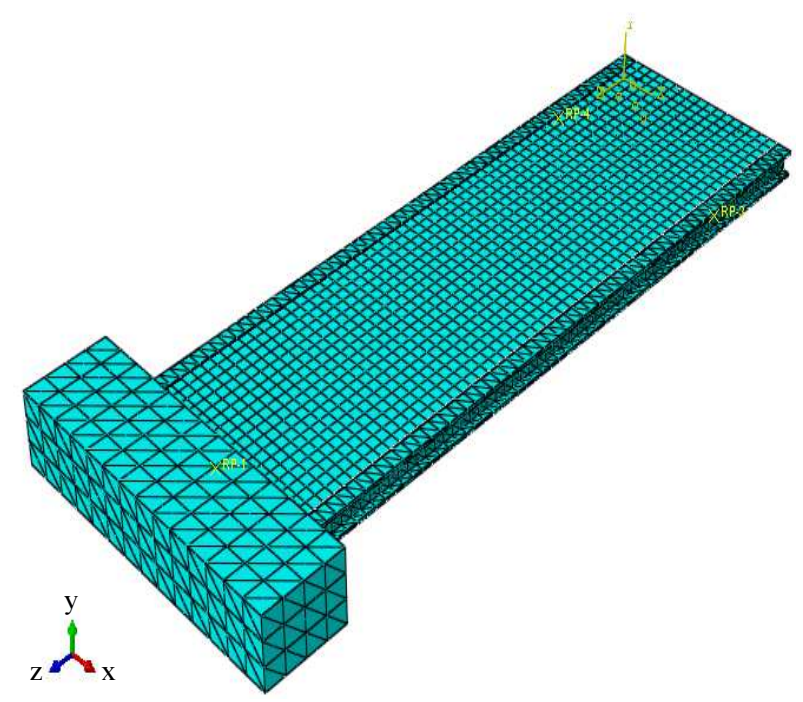

Fig. 9: Modeling of mesh

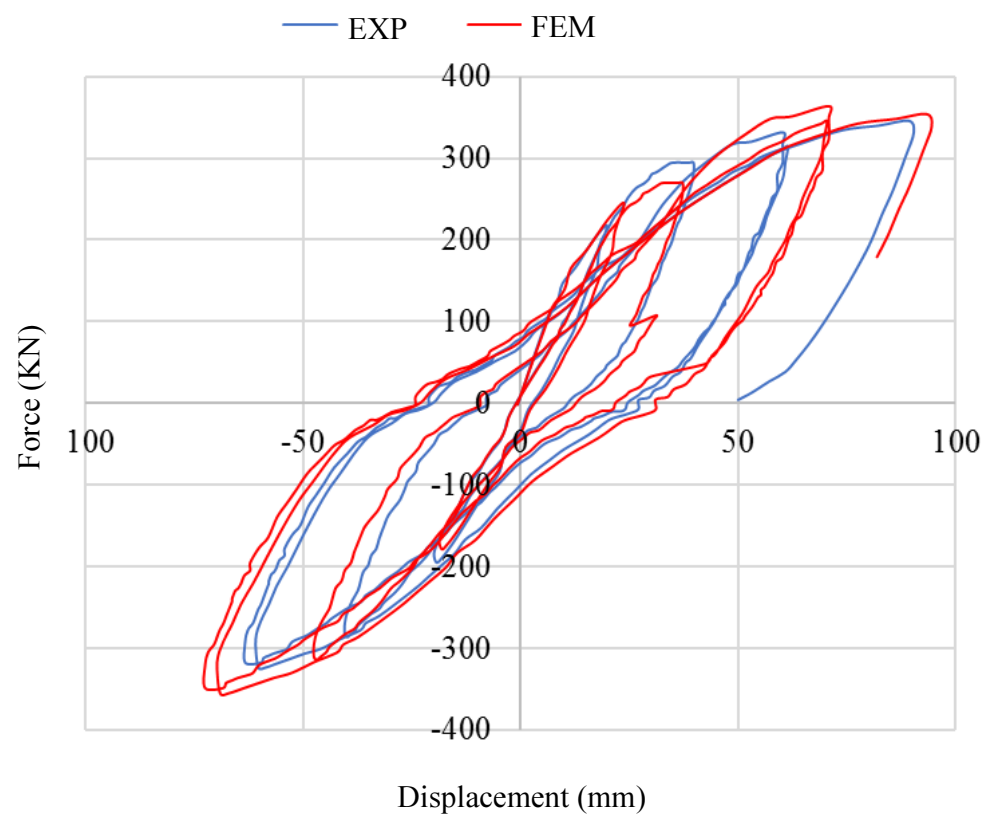

Fig. 10: The hysteresis force-displacement of laboratory and finite element model 


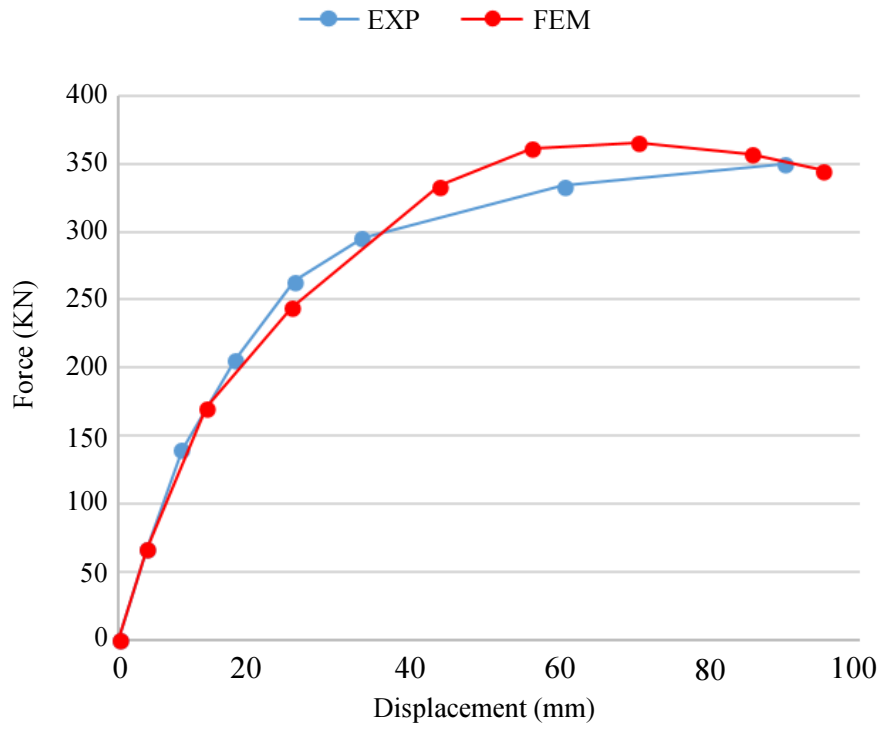

Fig. 11: The pushover force-displacement diagram of laboratory and finite element model

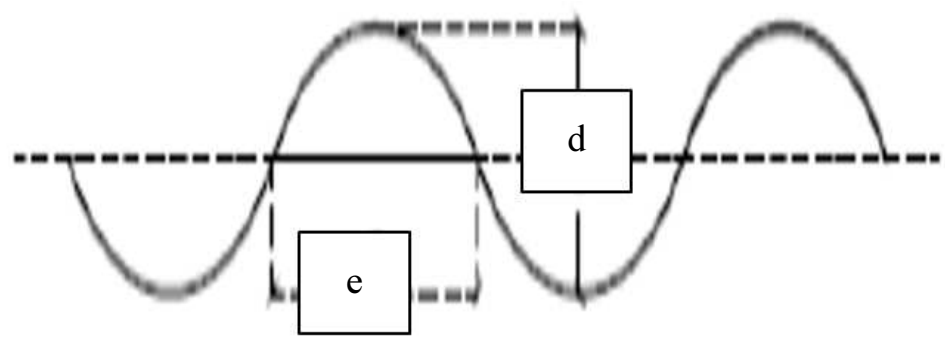

Fig. 12: Plate geometric of models

— Compressive-Fc35

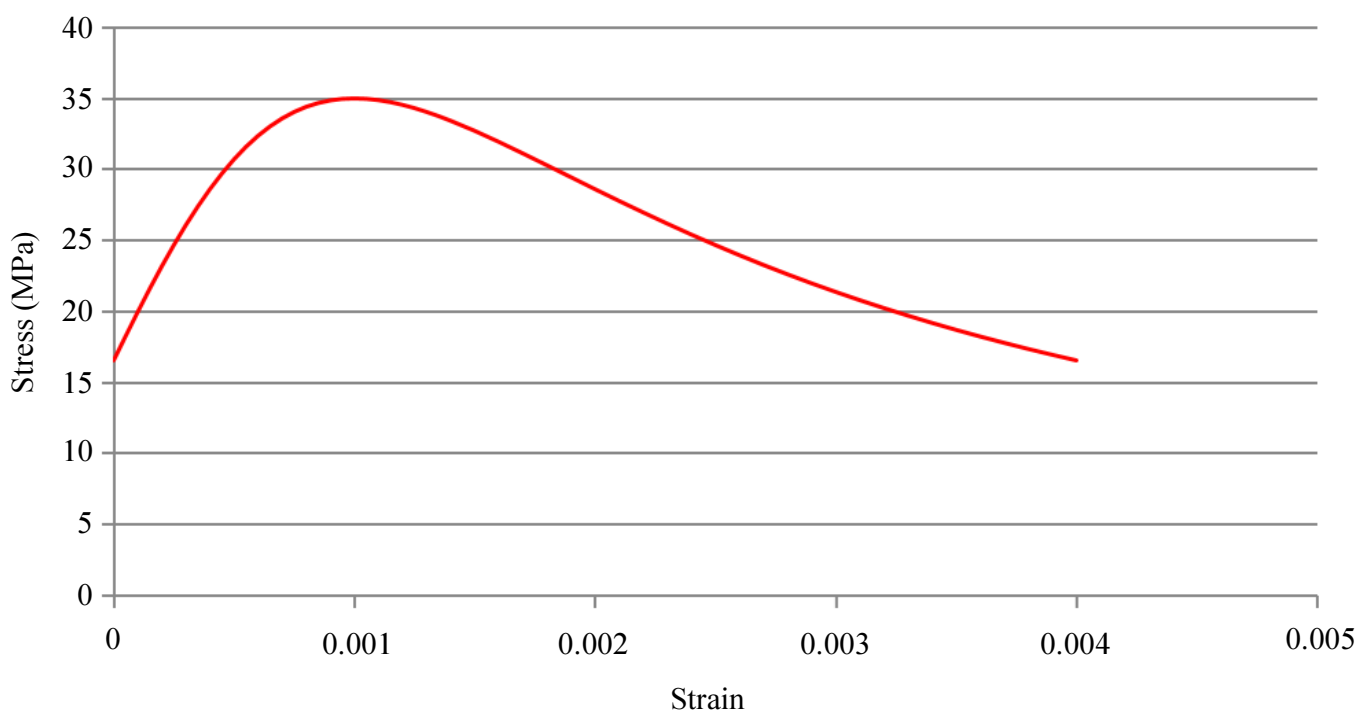

Fig. 13: Stress-strain diagram in the compression side in plastic area, compressive strength $35 \mathrm{MPa}$ 


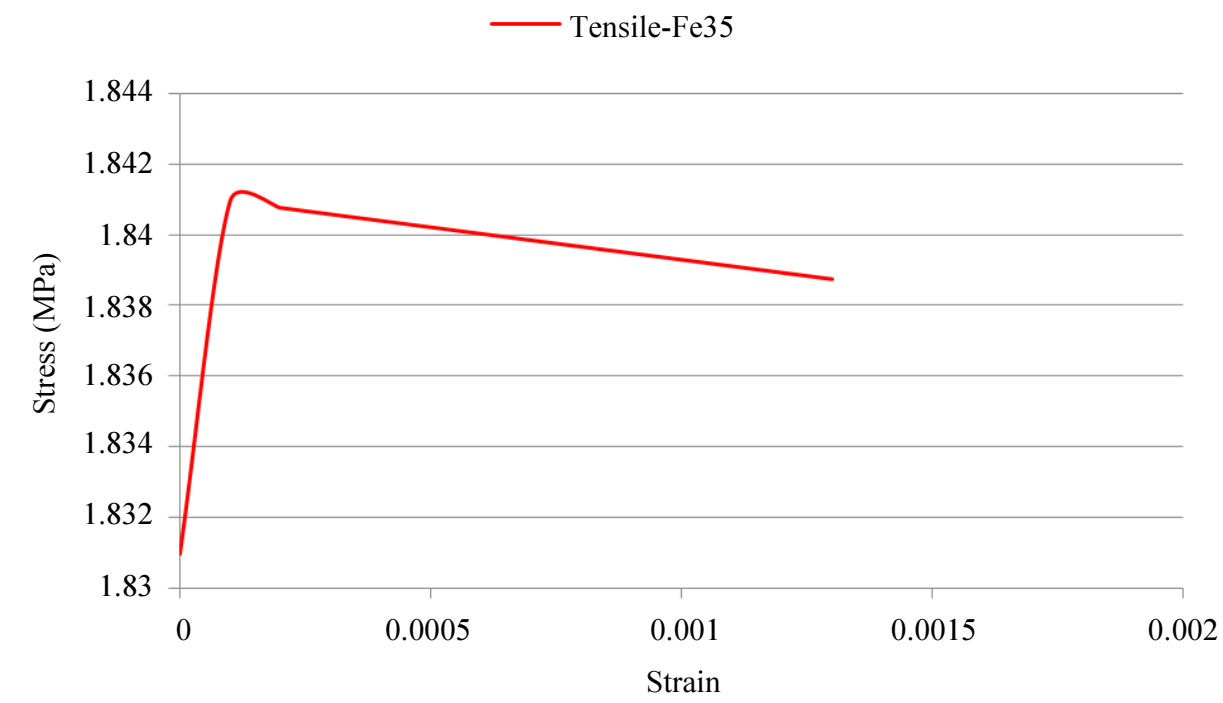

Fig. 14: Stress-strain diagram in the tensile side in plastic area, compressive strength $35 \mathrm{MPa}$

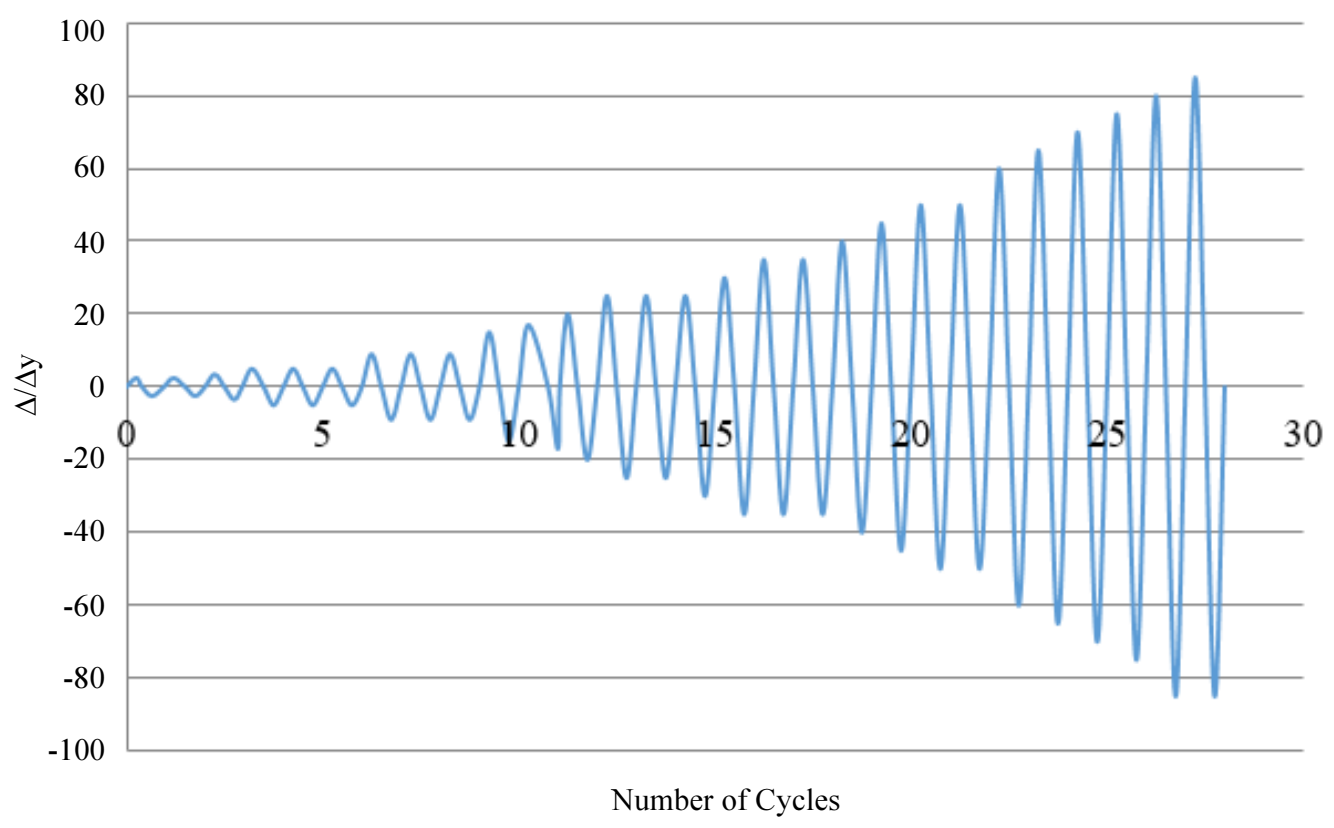

Fig. 15: Loading amplitude

Table 1: Model details

\begin{tabular}{lllllll}
\hline Code & $\begin{array}{l}\text { Wave } \\
\text { Step }(\mathrm{mm})\end{array}$ & $\begin{array}{l}\text { Wave } \\
\text { height }(\mathrm{mm})\end{array}$ & $\begin{array}{l}\text { Sheet } \\
\text { thickness }(\mathrm{mm})\end{array}$ & $\begin{array}{l}\text { Sheet } \\
\text { width }(\mathrm{mm})\end{array}$ & $\begin{array}{l}\text { Sheet } \\
\text { height }(\mathrm{mm})\end{array}$ & $\begin{array}{l}\text { Compressive } \\
\text { strength of concrete }\end{array}$ \\
\hline S1 & 75 & 25 & 0.8 & 1800 & 1200 & 25 \\
S2 & 75 & 50 & 0.8 & 1800 & 1200 & 25 \\
S3 & 75 & 25 & 1.0 & 1800 & 1200 & 25 \\
S4 & 75 & 50 & 1.0 & 1800 & 1200 & 25 \\
S5 & 75 & 25 & 0.8 & 1800 & 1200 & 35 \\
S6 & 75 & 50 & 0.8 & 1800 & 1200 & 35 \\
S7 & 75 & 25 & 1.0 & 1800 & 1200 & 35 \\
S8 & 75 & 50 & 1.0 & 1800 & 1200 & 35 \\
\hline
\end{tabular}


It should be noted that the stress of the steel sheets is $400 \mathrm{MPa}$ and the ultimate stress is $450 \mathrm{MPa}$ and its elastic modulus is $207000 \mathrm{MPa}$. In Fig. 13 and 14, the stresses-strain diagram of concrete with a compressive strength of $35 \mathrm{MPa}$ are shown.

Nonlinear General Static analysis has been used in the models and analysis of the loading amplitude was performed within $28 \mathrm{sec}$. The loading is also carried out in the form of gravity and lateral, so that for gravity loading, the load type is presureand for the lateral load, the control change considered constant. In Fig. 15, the loading amplitude is shown.

\section{Results and Discussion}

Table 1 shows the characteristics of each sample and in the Fig. 16 to 23 the results of the pushover diagram of each sample are given. All models are of a sinusoidal type. In the Fig. 16 model S1, it can be seen that, the maximum force is 589.934 and also the maximum displacement is $70 \mathrm{~mm}$, compared to the original sample, it has a $70.68 \%$ increase in force and $26.1 \%$ reduction in displacement. The buckling sections of the beam and the column are clearly visible. Also, the place of loading is the most critical area.

In the Fig. 17 model $\mathrm{S} 2$, the maximum force is 816.07 KN, as well as the maximum displacement of $70 \mathrm{~mm}$, which, in comparison with the original sample, has $136.11 \%$ increase in force and $26.1 \%$ reduction in displacement. In model S3 is shown in the Fig. 18, the maximum force is $613.991 \mathrm{KN}$, also the maximum displacement of $75 \mathrm{~mm}$, which, in comparison with the original sample, has $77.46 \%$ increase in force and $20.85 \%$ reduction in displacement. Figure 19 indicates the model S4, the maximum force is $866.433 \mathrm{KN}$, also the maximum displacement of $75 \mathrm{~mm}$, which in comparison with the original sample, has $150.68 \%$ increase in force and $20.85 \%$ reduction in displacement. By comparing samples S3 and S4, it can be concluded that due to the constant thickness and compressive strength of the concrete and the wall dimensions, with increasing wavelengths from 25 to 50 $\mathrm{mm}$, the amount of force increased.

In model $\mathrm{S} 5$ in the Fig. 20, the maximum force is $746.114 \mathrm{KN}$, also the maximum displacement of 78.43 $\mathrm{mm}$, which, in comparison with the original sample, has $115.87 \%$ increase in force and $17.23 \%$ reduction in displacement. Because of the lateral load and compression load, most of the steel areas are broken and this is at the column, beam and plate sections. In model S6 shows in the Fig. 21, the maximum force is $977.399 \mathrm{KN}$, also the maximum displacement of 81 $\mathrm{mm}$, which, in comparison with the original sample, has $182.79 \%$ increase in force and $14.52 \%$ reduction in displacement. By comparing samples S5 and S6, it can be included that due to the constant thickness and compressive strength of the concrete and the wall dimensions, with increasing wavelengths from 25 to 50 $\mathrm{mm}$, the amount of force increased.

In the Fig. 22 regarding the model S7, the maximum force is $801.249 \mathrm{KN}$, also the maximum displacement of $90.21 \mathrm{~mm}$, which, in comparison with the original model, has $131.82 \%$ increase in force and $4.8 \%$ reduction in displacement. In model S8 depicts in the Fig.23, the maximum force is $1034.37 \mathrm{KN}$, also the maximum displacement of $89.74 \mathrm{~mm}$, which, in comparison with the original sample, has $199.27 \%$ increase in force and 5.3\% reduction in displacement. By comparing samples $\mathrm{S} 7$ and S8, it can be included that due to the constant thickness and compressive strength of concrete and the wall dimensions, with increasing wavelengths from 25 to 50 $\mathrm{mm}$, the amount of force increased.

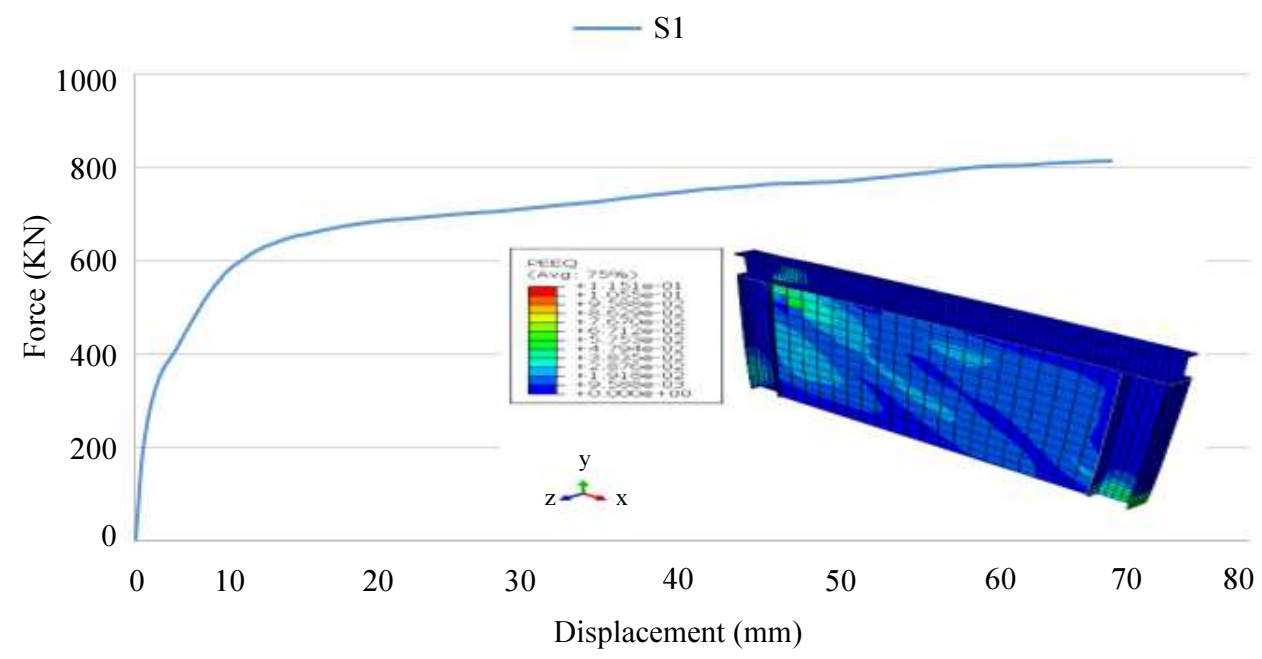

Fig. 16: Load-displacement diagram for model S1 


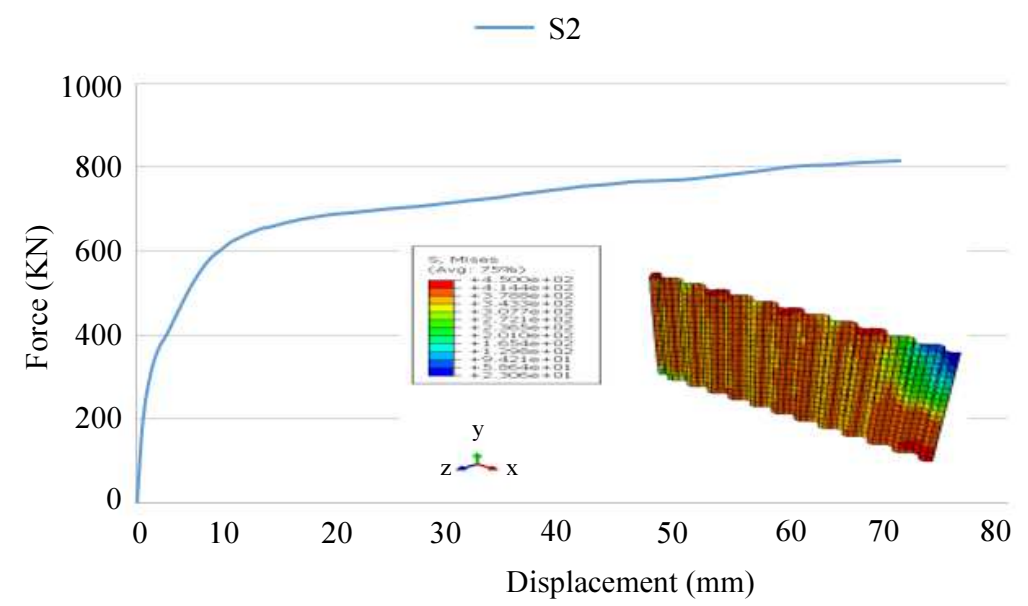

Fig. 17: Load-displacement diagram for model S2

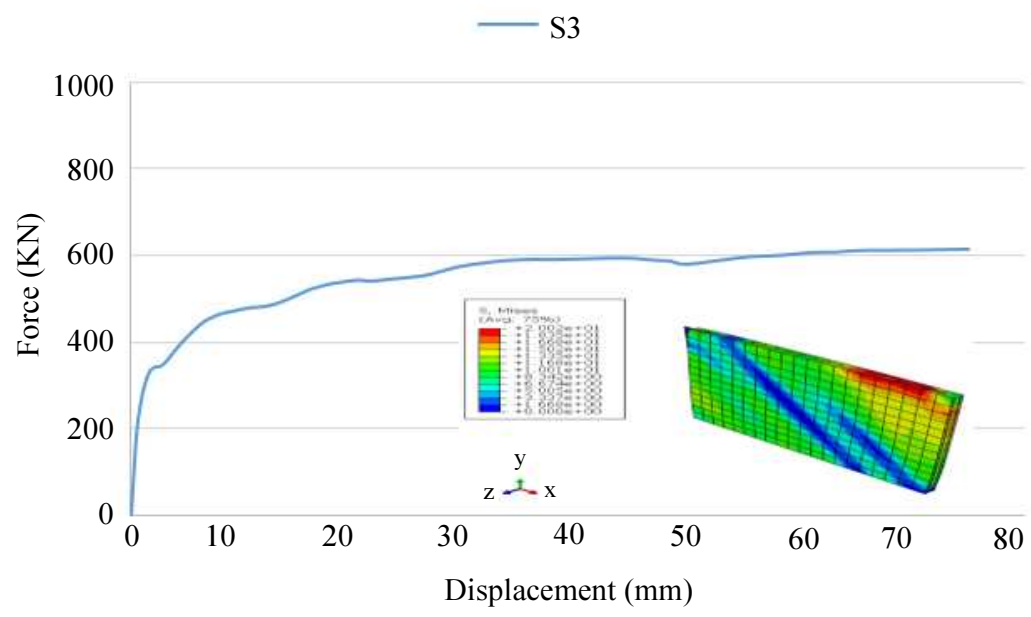

Fig. 18: Load-displacement diagram for model S3

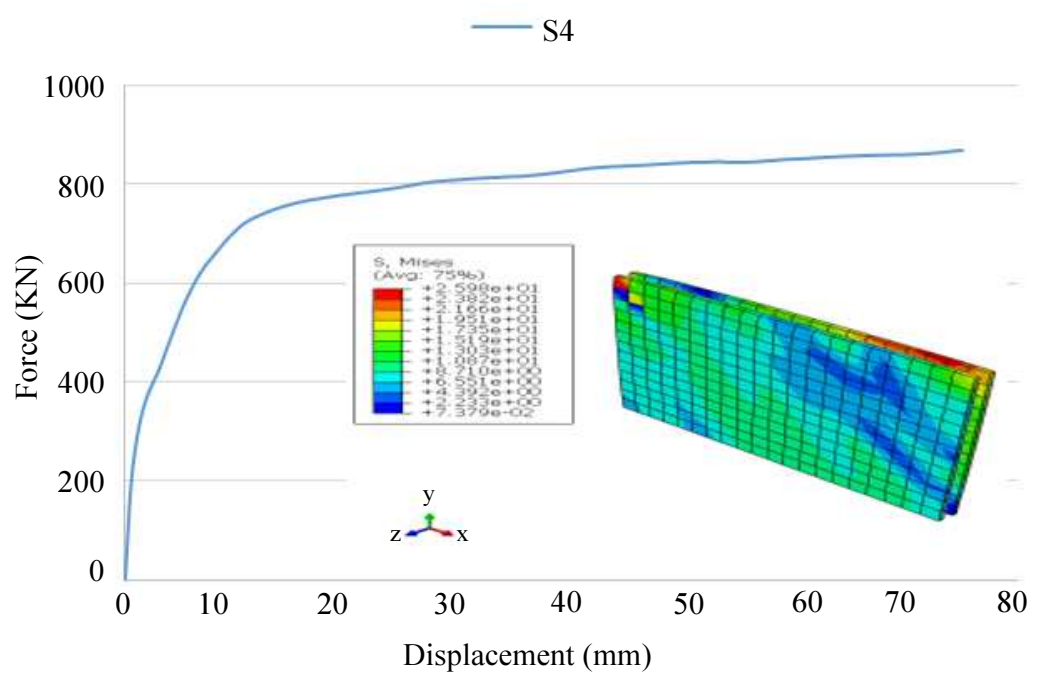

Fig. 19: Load-displacement diagram for model S4 


\section{$-\mathrm{S} 5$}

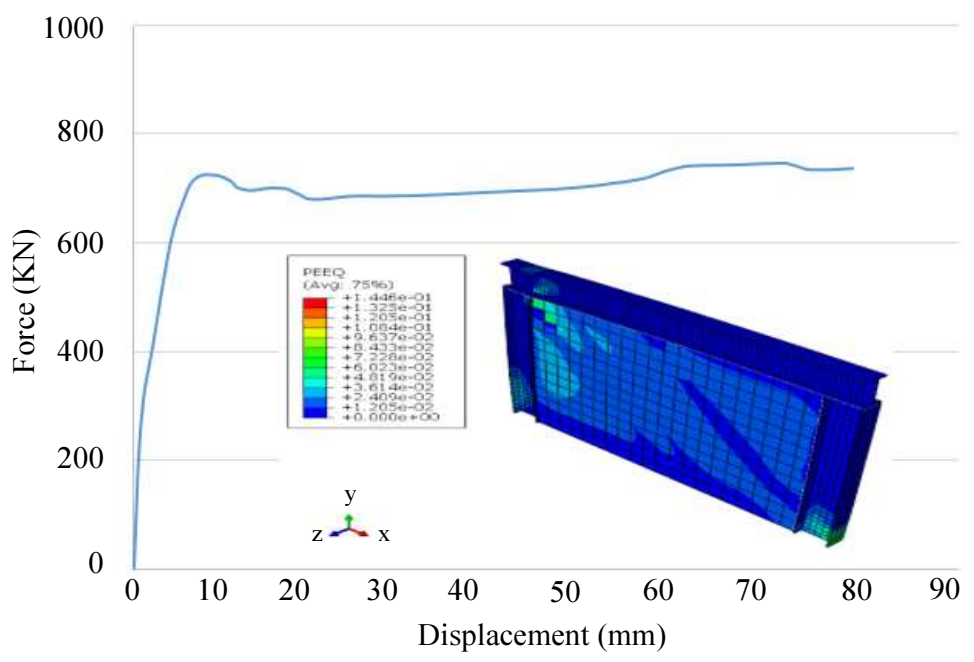

Fig. 20: Load-displacement diagram for model S5

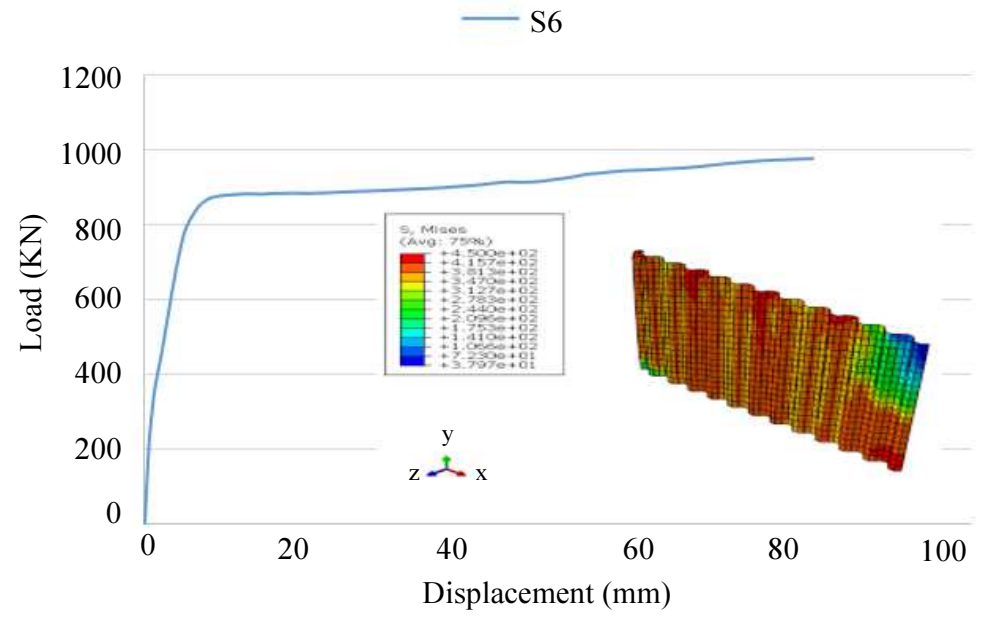

Fig. 21: Load-displacement diagram for model S6

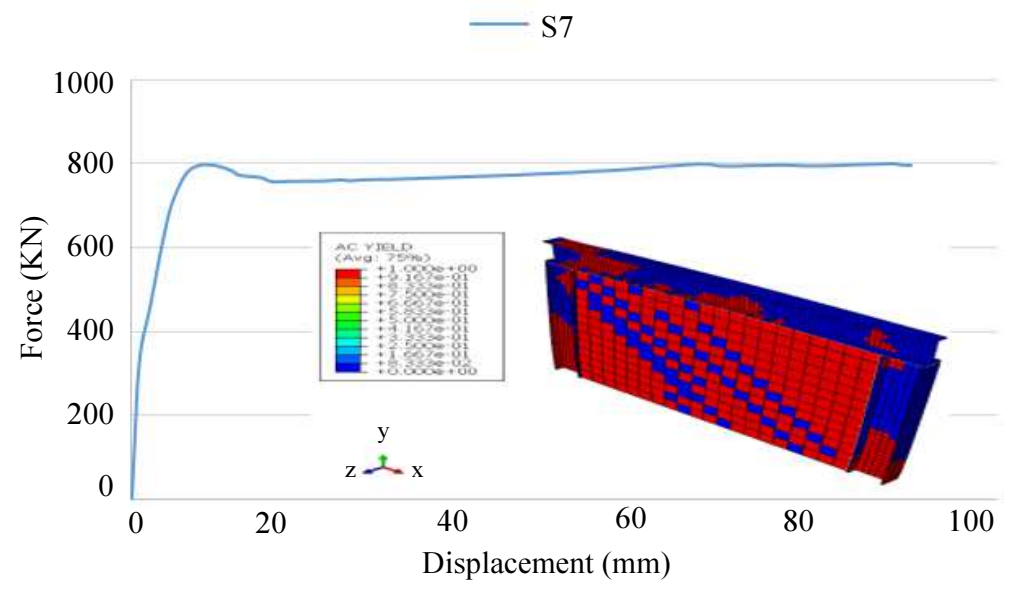

Fig. 22: Load-displacement diagram for model S7 


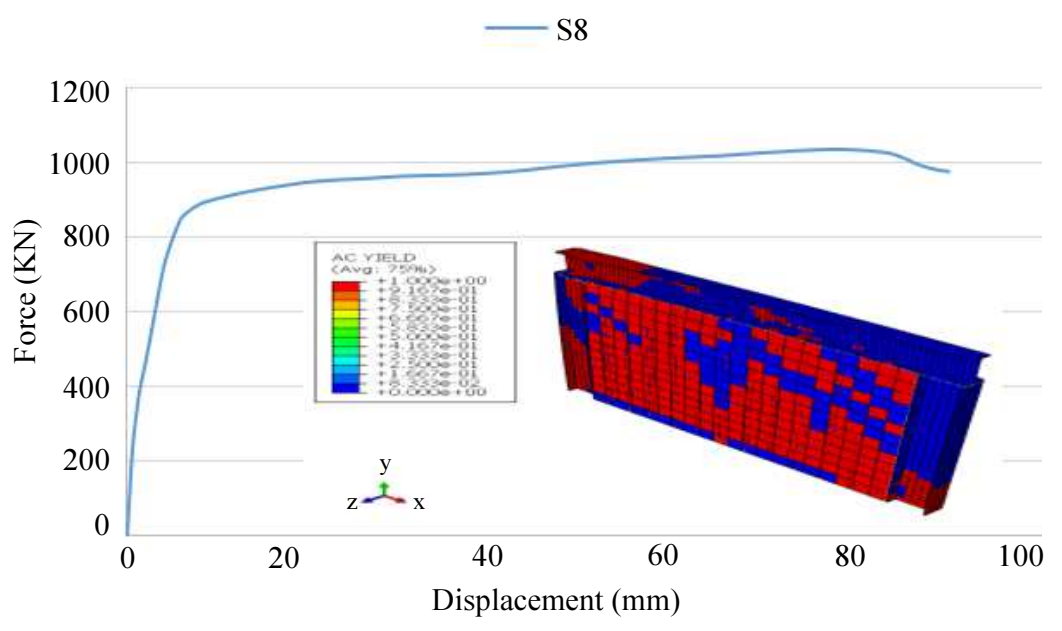

Fig. 23: Load-displacement diagram for model S8

$$
1200
$$

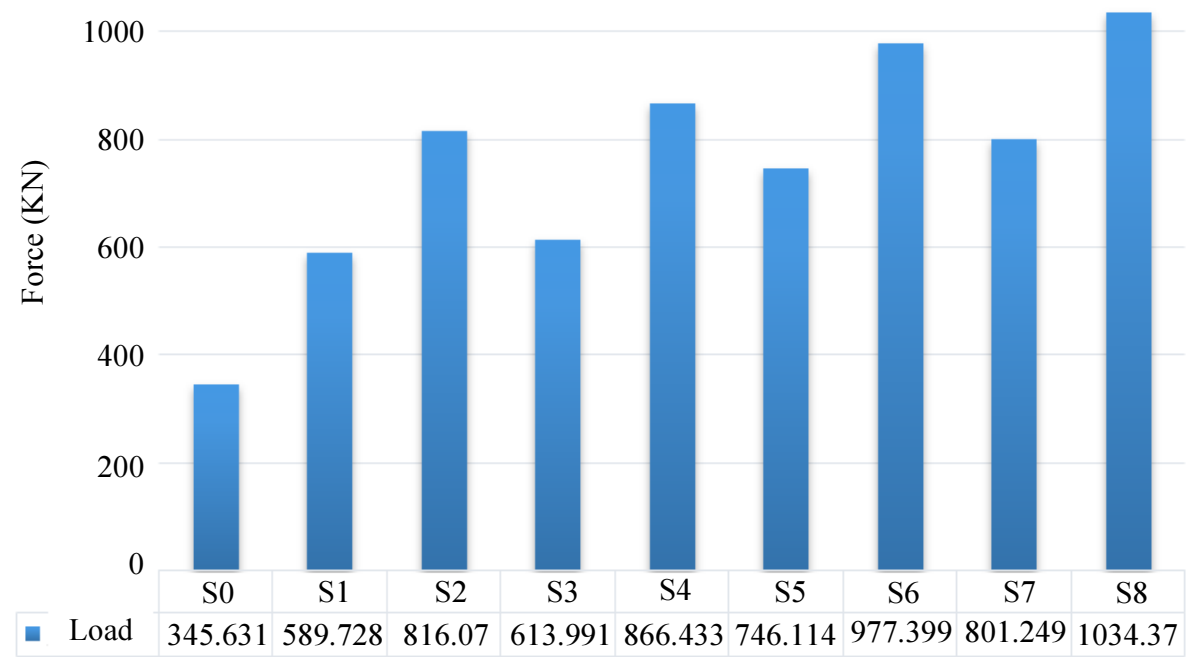

Fig. 24: Evaluation of the maximum load capacity for the sinusoidal corrugated plate

Comparison of the pushover of sinusoidal corrugated sheets with 75 wave step, 25 wavelengths and $0.8 \mathrm{~mm}$ thickness with 25 and $35 \mathrm{MPa}$ resistance shows that increased compressive strength leads to increased force and displacement. For example, for samples S1 and S5, respectively, the force is 589.728 and $746.114 \mathrm{KN}$ and the displacement is 70 and $78.43 \mathrm{~mm}$, which is an increase of $26.51 \%$ and $12.04 \%$ in force and displacement relative to each other.

Similarly, with a change in the thickness of the sheet from 0.8 to $1 \mathrm{~mm}$, this force and displacement ratio is more than that, so that the increase percentage is typically equal to $25 \mathrm{MPa}$ for the compressive strength of $35 \mathrm{MPa}$, respectively, equal to 7.39 and $15.01 \%$. This figure is shown in the graphs below. In general, it can be included that the increase in wavelength from $25 \mathrm{~mm}$ to $50 \mathrm{~mm}$, the increase in thickness from 0.8 to $1 \mathrm{~mm}$ and the increase in compressive strength from 25 to $35 \mathrm{MPa}$ resulted in increased force and displacement. In such a way, the structure with greater displacement will have more ductility. Figure 24 and 25 show the values of force and displacement in the samples. A summary of the results is also given in Table 2. As shown, the highest force in sample S8 is that of a sinusoidal sheet with a wave height of $50 \mathrm{~mm}$ and a thickness of $1 \mathrm{~mm}$ and compressive strength of concrete of $35 \mathrm{MPa}$. 


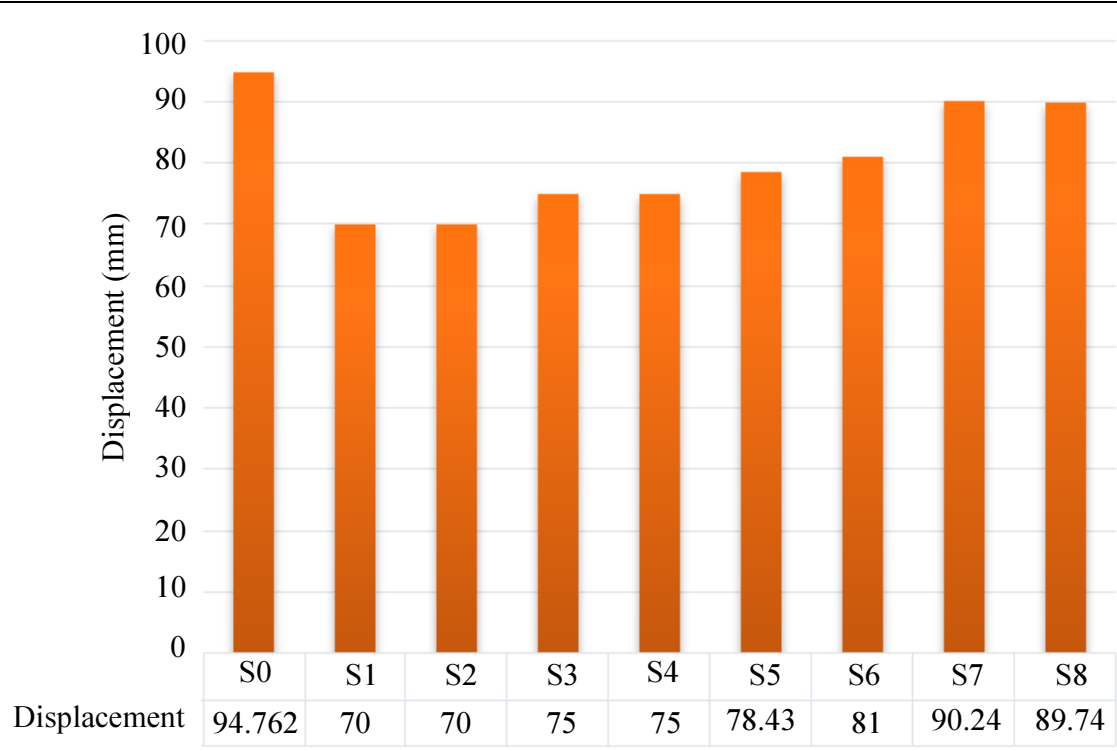

Fig. 25: Evaluation of the maximum displacement for the sinusoidal corrugated plate

Table 2: Summary of model results

\begin{tabular}{|c|c|c|c|c|}
\hline $\begin{array}{l}\text { Percentage reduction in displacement } \\
\text { relative to the prototype }\end{array}$ & $\begin{array}{l}\text { Percentage of force increasing } \\
\text { relative to the prototype }\end{array}$ & $\begin{array}{l}\text { Displacement } \\
(\mathrm{mm})\end{array}$ & Force $(\mathrm{KN})$ & Sample \\
\hline 1.26 & 68.700 & 70.00 & 728.58900 & $\mathrm{~S} 1$ \\
\hline 26.1 & 11.136 & 70.00 & 7.81600 & $\mathrm{~S} 2$ \\
\hline 85.2 & 64.770 & 75.00 & 0.99613 & S3 \\
\hline 85.2 & 68.150 & 75.00 & 433.86600 & S4 \\
\hline 23.17 & 87.115 & 43.78 & 114.74600 & S5 \\
\hline 52.14 & 79.182 & 81.00 & 399.97700 & S6 \\
\hline 0.84 & 82.131 & 21.90 & 249.80100 & S7 \\
\hline 3.5 & 27.199 & 74.89 & 37.10340 & S8 \\
\hline
\end{tabular}

\section{Conclusion}

In this study, at first validation was done, which is a steel shear wall, one floor and single span, for verification with thickness of $100 \mathrm{~mm}$, width of 1000 and length of $3000 \mathrm{~mm}$. The compressive strength of the wall is $25 \mathrm{MPa}$ and the surrender and ultimate tension of the longitudinal bars are 479 and $616 \mathrm{MPa}$, respectively and these values for the cross bars are 548 and $622 \mathrm{MPa}$, respectively. Nonlinear static analysis was used in the models and analysis was performed by applying load domain in 28 seconds. The loading is also made in the form of a gravity and lateral, so that for gravity load, the load type is compression and for the lateral load, the control change is used. It should be noted that the displacement and applied pressure for all samples are considered constant.

Validation and comparison of software and laboratory samples were in good agreement and the maximum force obtained in the laboratory was $345.97 \mathrm{KN}$, which increased the maximum force in ABAQUS by $4.5 \%$ and reached $363.77 \mathrm{KN}$. On the other hand, the sample space of the laboratory is 90.36 , which resulted in a software increase of $5.1 \%$ to $94.5 \mathrm{~mm}$. Due to the comparison of the results and the small differences between the software and the results, it can be concluded that the finite element model presented has an acceptable accuracy. In the following chapter, for the purpose of performing a parametric study on the effect of the geometry of the sheets of steel shear wall with rippling plate, thin 0 walled sinusoidal specimens were subjected to pressure and lateral loading and the results were examined.

In this parametric study, the specimens had the same characteristics and their differences was in the geometry of the thin sheet steel shear walls. The finite element model of corrugated specimens was investigated based on the loading pattern of the force-displacement diagram.

In the following, the results are case studies:

- Comparing the corrugated sinusoidal specimens increasing the compressive strength from 25 to 35 , for the same thickness, increases the strength and plasticity

- Comparing the corrugated sinusoidal specimens, with the same strength and thickness, with increasing wavelengths from 25 to $50 \mathrm{~mm}$, leads to increased resistance and ductility

- Comparing the force and displacement of the sheets, the results indicate that the sinusoidal sheet with wave step of $75 \mathrm{~mm}$, wavelengths of $50 \mathrm{~mm}$, thickness of $1 \mathrm{~mm}$ and compressive strength of 35 
$\mathrm{MPa}$, has a higher force than the other sheets and also change of the location of the sinusoidal sheet with a compressive strength of $35 \mathrm{MPa}$ is more than the other sheets

- At the end of the conclusion, the sinusoidal sheet in sample S8 has a better performance than the other sheets in terms of force and displacement. Also, thin terms of plasticity, the sinusoidal sheet will perform better

\section{Ethics}

This article is an original research paper. There are no ethical issues that may arise after the publication of this manuscript.

\section{References}

ABAQUS Documentation Analysis User's Manual version6.11.

Abu-Lebdeh, T.M. and G.Z. Voyiadjis, 1993. A damage model for concrete using the bounding surface concept. J. Eng. Mechan., 119: 1865-1885.

DOI: 10.1061/(ASCE)0733-9399(1993)119:9(1865)

Abu-Lebdeh, T.M. and G.Z. Voyiadjis, 1993. Plasticitydamage model for concrete under cyclic multiaxial loading. J. Eng. Mechan., 119: 1465-1484.

Berman, J.W and M. Bruneau, 2003. Exprimental investigation of light-gauge steel plate shear walls for the seismic retrofit of buildings. Multidisciplinary Center for Earthquake Engineering Research, Multidisciplinary Center for Eartquake Engineering Research, Technical Report MCEER-03-0001, Buffalo.

Dan, D., A. Fabian and V. Stoian, 2011. Theoretical and experimental study on composite steel-concrete shear walls with vertical steel encased profiles. J. Construct. Steel Res., 67: 800-813. DOI: $10.1016 /$ j.jcsr.2010.12.013

Driver, R.G., G.L. Kulak and D.J.L. Kennedy, 1997. Seismic behaviors of steel plate shear walls. Structural Engineering, Rep No. 215, Dept. of Civil Engineering, University of Alberta, Edmonton, Alta, Canada.

Emami, F., M. Mofid and A. Vafai, 2013. Experimental study on cyclic behavior of trapezoidally corrugated steel shear walls. Eng. Structures, 48: 750-762. DOI: $10.1016 /$ j.engstruct.2012.11.028

Fallahi, M., S. SayyarRoudsari, M. Haghighfar and R. Madandoust, 2018. Modeling of reinforced concrete frames with Infill walls under cyclic loading Strengthening with CFRP. Am. J. Eng. Applied Sci.

Fanaie, N., S. Kazerani, and S. Soroushnia, 2015a. Numerical Study of slotted web drilled flange moment frame connection. J. Numerical Meth. Civil Eng., 1: 16-23.
Fanaie, N., F.G. Esfahani, and S. Soroushnia, 2015b. Analytical study of composite beams with different arrangements of channel shear connectors. Steel Composite Struct., 19: 485-501.

Faramarzpour, A. and A. Laman Jeffrey, 2015. Behavior prediction of corrugated steel plate shear walls with openings. J. Construct. Res., 114: 258-268.

DOI: $10.1016 /$ j.jcsr.2015.07.018

Hosseinpour, M., S. Baharom and Y. Yadollahi, 2015. Evaluation of steel shear walls behavior with sinusoidal and trapezoidal corrugated plates. Adv. Civil Eng., 2015: 715163-715163.

DOI: $10.1155 / 2015 / 715163$

Kazerani, S., N. Fanaie, and S. Soroushnia, 2017. Seismic behavior of drilled beam section in moment connections. J. Numerical Meth. Civil Eng., 1: 1-6.

Prabha, P., G.S. Palani, N. Lakshmanan and R. Senthil, 2017. Behaviour of steel-foam concrete composite panel under in-plane lateral load. J. Construct. Steel Res., 139: 437-448.

DOI: $10.1016 /$ j.jcsr.2017.10.002

Rahnavard, R., A. Hassanipour and M. Mounesi, 2016. Numerical study on important parameters of composite steel-concrete shear walls. J. Construct. Steel Res., 121: 441-456. DOI: $10.1016 /$ j.jcsr.2016.03.017

SayyarRoudsari, S., S.A. Hamoush, S.M. Soleimani and R. Madandoust, 2018. Evaluation of large-size reinforced concrete columns strengthened for axial load using fiber reinforced polymers. Eng. Structures.

SayyarRoudsari, S., S.A. Hamoush, S.M. Soleimani, T.A. Lebdeh and M. Haghighfar, 2018. Analytical study of reinforced concrete beams strengthened by FRP bars subjected to impact loading condition. Am. J. Eng. Applied Sci. DOI: 10.3844/ofsp.11916

Shabana, M. and A. Alibeigloo, 2017. Threedimensional elasticity solution for sandwich panels with corrugated cores by using energy method. Thin-Walled Structures, 119: 404-411. DOI: $10.1016 /$ j.tws.2017.06.035

Soleimai, M.S. and S. SayyarRoudsari, 2015. Analytical study of reinforced concrete beams tested under impact loading. Proceedings of the 4th International Workshop Performance Protection Strengthening Structures Under Extreme Loading, Jun. 28-30, pp: 620-627.

Voyiadjis, G.Z. and T.M. Abu-Lebdeh, 1994. Plasticity model for concrete using the bounding surface concept. Int. J. Plasticity, 10: 1-22. DOI: 10.1016/0749-6419(94)90051-5

$\mathrm{Yu}, \mathrm{C}$. and G. Yu, 2016. Experimental investigation of cold-formed steel framed shear wall using corrugated steel sheathing with circular holes. J. Structural Eng., 142: 04016126-04016126. DOI: $10.1061 /(A S C E) S T .1943-541 X .0001609$ 